\title{
Low Levels of Tumor Necrosis Factor- $\alpha$ will Prevent Periodontitis Exacerbation in Type 2 Diabetes Mellitus
}

\author{
Titiek Berniyanti ${ }^{1}$ Gilang Rasuna Sabdho Wening ${ }^{1}$ Retno Palupi ${ }^{1}$ Dini Setyowati ${ }^{1}$ \\ Cindy Ramadhan Putri² \\ ${ }^{1}$ Department of Dental Public Health, Faculty of Dental Medicine, \\ Universitas Airlangga, Surabaya, Indonesia \\ 2 Faculty of Dental Medicine, Universitas Airlangga, Surabaya, \\ Indonesia \\ Address for correspondence Titiek Berniyanti, drg. M.Kes, \\ Department of Dental Public Health, Faculty of Dental Medicine, \\ Universitas Airlangga, Jl. Mayjen. Prof. Dr. Moestopo no. 47, Surabaya \\ 60132 Indonesia \\ (e-mail: titiek-b@fkg.unair.ac.id; berniyanti65@gmail.com).
}

Eur J Dent 2022;16:443-448.

\begin{abstract}
Keywords

- healthy lifestyle

- TNF- $\alpha$

- diabetes

- periodontitis

- behavior

Objectives Diabetes mellitus (DM) is a major risk factor for periodontitis. Susceptibility to periodontitis increases approximately three times in people with DM. There is a clear relationship between the degree of hyperglycemia and the severity of periodontitis. This study aimed to analyze the reduction of tumor necrosis factor- $\alpha$ (TNF- $\alpha$ ) in diabetics who came for periodontitis examination to prevent exacerbations.

Materials and Methods This was an analytic observational study using a crosssectional approach at health centers in Surabaya, Indonesia. Measurement of periodontal status used the community periodontal index of treatment needs by measuring bleeding at probing and pocket depth. TNF- $\alpha$ was measured using enzyme-linked immunosorbent assay, and behavior and lifestyle using a questionnaire.

Statistical Analysis The Kolmogorov-Smirnov test was performed to identify data normality $(p<0.05)$. A nonparametric test was used to measure the degree of association between different characteristics and the incidence of periodontitis in type 2 DM patients with and without periodontitis. Spearman's test was done to examine the correlation between TNF- $\alpha$ level and severity of periodontitis in diabetics. The significant level was at $p<0.05$.

Results There was a correlation between age, predisposing factors, reinforcing factors, drug consumption, and TNF- $\alpha$ levels in patients with type 2 DM and the incidence of periodontitis.

Conclusions Poor glycemic control can induce oxidative stress on the gingiva, thereby aggravating damage to periodontal tissue. An important factor in preventing periodontitis for type $2 \mathrm{DM}$ patients is controlling blood sugar levels through regular consumption of drugs and regular maintenance of oral cavity health. Knowledge is a predisposing factor that affects adherence of people with type $2 \mathrm{DM}$ to consuming drugs regularly, which can be strengthened by family support. These will ultimately play a role in reducing TNF- $\alpha$ levels.
\end{abstract}

published online January 11, 2022
DOI https://doi.org/ $10.1055 / \mathrm{s}-0041-1739442$. ISSN 1305-7456. (c) 2022. The Author(s).

This is an open access article published by Thieme under the terms of the Creative Commons Attribution License, permitting unrestricted use, distribution, and reproduction so long as the original work is properly cited. (https://creativecommons.org/licenses/by/4.0/)

Thieme Medical and Scientific Publishers Pvt. Ltd., A-12, 2nd Floor, Sector 2, Noida-201301 UP, India 


\section{Introduction}

Diabetes mellitus (DM) is a metabolic disorder characterized by hyperglycemia due to abnormal insulin secretion. The common symptoms of DM are polyuria, polydipsia, polyphagia, and weight loss. ${ }^{1}$ People with DM in the world in 2013 were 382 million and will continue to increase up to 592 million in 2035. 2,3 Basic Health Research in 2013 reported that the prevalence of DM in Indonesia increased from $1.1 \%$ in 2007 to $2.1 \%$ in 2013 , and approximately $95 \%$ of them were type $2 \mathrm{DM}$, which tended to be caused by an unhealthy lifestyle. Type 2 DM can be prevented by controlling risk factors such as people's behavior and lifestyle. Periodontitis is the most common complication in DM patients with a prevalence rate of $75 \%$. Based on the study, there were 118 people (93.7\%) of 126 DM patients in 2008 who suffered from periodontitis. $^{4}$ It is an inflammatory process that occurs in the supporting tissues of the teeth in response to the accumulation of bacteria, or plaque on the teeth, and affects the adhesion of the connective tissue and supporting bone around the teeth. ${ }^{5}$ Several studies have shown that the severity of periodontitis in DM patients is greater, especially in uncontrolled patients.

DM is classified into three types. Type 1 DM usually occurs in adolescents or children due to cell damage that is thought to be due to an autoimmune process. Type $2 \mathrm{DM}$ in adults is due to decreased insulin receptor sensitivity resulting from worsening risk factors, such as overweight and lack of physical activity. Then the third type is gestational DM (GDM)-a diabetes that is diagnosed during pregnancy with signs of hormonal hyperglycemia. ${ }^{3}$

Criteria for determining DM are as follows: sugar levels $>126 \mathrm{mg} / \mathrm{dL}$, random blood sugar $>200 \mathrm{mg} / \mathrm{dL}$, and $\mathrm{HbA} 1 \mathrm{c}$ examination every 2 to 3 months with DM criteria $>6.5-$ $7 \%{ }^{6-8}$ Type $2 \mathrm{DM}$ is strongly influenced by risk factors. These factors can be changed through behavior and lifestyle modification. Behavior is a person's reaction to a stimulus. The behavior occurs through a stimulus process in the organism and then the organism responds. Behavior and lifestyle play an important role in controlling type 2 diabetes and periodontitis. Behavior modification is very important to control blood glucose levels and reducing the prevalence of DM, both in Indonesia and around the world. ${ }^{9}$ A person's health behavior is influenced by three factors: predisposing factors, enabling factors, and reinforcing factors. ${ }^{9,10}$ According to the World Health Organization, a healthy lifestyle is a lifestyle that can reduce the risk of disease or premature death from disease, which takes into account certain factors that affect health, including diet and exercise. ${ }^{3}$ Immune response has a great role in the severity of inflammation in periodontitis. ${ }^{11}$ Bacteria produce inflammatory mediators, such as prostaglandins or cytokines, including tumor necrosis factor- $\alpha$ (TNF- $\alpha$ ) and interleukin-1. These mediators stimulate the production and activation of enzymes so that they can damage gingival connective tissue and produce osteoclasts that can absorb bone. ${ }^{12}$

Poor blood sugar control and increased advanced glycation end-product (AGE) formation induce oxidative stress in the gingiva which will slow the breakdown of the periodontium tissue. Increased levels of inflammatory cells in the gingival crevicular fluid (GCF) also make the periodontium tissue more susceptible to infection and cause bone damage. Apart from damaging the leukocytes, another complication of DM is blood-vessel thickening which limits the flow of nutrients in the body. A slow blood flow will reduce the body's ability to heal infections so that periodontitis will get worse in people with diabetes. These are the factors that affect the periodontium condition in people with diabetes. ${ }^{13}$ This study aimed to analyze the reduction of TNF- $\alpha$ in people with diabetes who came for periodontitis examination to prevent exacerbations.

\section{Materials and Methods}

This was an observational analytic study with a cross-sectional approach, conducted after obtaining ethical permission from the Faculty of Dental Medicine Universitas Airlangga, Surabaya, Indonesia, with Licensing Certificate Number 133/HRECC.FODM/VII/2018. A total of 90 DM type 2 respondents with and without periodontitis were taken as samples. This study conformed to the STROBE guidelines with a checklist attached as a proof.

All respondents were elderly in Surabaya suffering from type 2 DM. Medical facilities in Surabaya were selected using cluster random sampling to obtain six health centers with 90 respondents. The confidence level was $90 \%$. The inclusion criteria of respondents established to prevent bias were elderly people aged $>45$ years and suffering from type 2 diabetes. Respondents who were willing to take part in this study signed informed consent. All respondents were asked to fill out a questionnaire consisting of the respondent's behavior (predisposing factors, enabling factors, and reinforcing factors) and the respondent's lifestyle (diet, physical activity, maintenance of the oral cavity, and smoking habits). The predisposing factors included respondents' knowledge about type $2 \mathrm{DM}$ and its impact on oral health; the enabling factors include the availability of costs and access to health services; while the reinforcing factors included family support for respondents in maintaining their health.

After filling out the questionnaire, the respondents were checked for periodontal status using the community periodontal index of treatment needs (CPITN), which included the amount of bleeding on probing and the depth of the pocket. In addition, the TNF- $\alpha$ level was measured by ELISA (enzyme-linked immunosorbent assay) to the respondent's saliva. As much as $5 \mathrm{~mL}$ of saliva was produced through stimulation by chewing a tampon. The collected saliva was examined for TNF- $\alpha$ levels using an ELISA kit to determine the correlation between TNF- $\alpha$ levels and the incidence of periodontitis in type 2 DM patients.

For statistical analysis, the Kolmogorov-Smirnov test was done to identify data normality with $p<0.05$. A nonparametric test was used to measure the degree of correlation between different characteristics and the incidence of periodontitis in type 2 DM patients with and without periodontitis. Spearman's test was done to examine the correlation of 
TNF- $\alpha$ level and severity of periodontitis in those diabetics with a significance level of $p<0.05$.

\section{Result}

Age was found to have a significant difference with $p=0.042$ $(p<0.05)$, showing that the older the patient, the higher the risk of type $2 \mathrm{DM}$. Whereas, the variables of the duration of suffering and family history did not have a significant correlation with the incidence of periodontitis in patients with type 2 DM (-Table 1). The predisposing factors, which were represented by knowledge, had a significant correlation with periodontitis ( $p$-value $=0.000, p<0.05$ ), and so did the reinforcing factors $(p=0.012, p<0.05)$. The enabling factors did not have a significant correlation with the incidence of periodontitis in patients with type $2 \mathrm{DM}$ (-Table 2). A good diet with fruit and vegetable consumption was found not to have a significant correlation, and so were the physical activity, management of oral cavity, and smoking, but not for drug consumption with $p=0.044$ ( - Table 3). There was a

Table 1 Correlation between different characteristics and the incidence of periodontitis in type 2 diabetes mellitus patients with and without periodontitis

\begin{tabular}{|c|c|c|c|c|c|c|}
\hline \multicolumn{7}{|l|}{ Diabetes mellitus } \\
\hline \multirow[t]{2}{*}{ Variables: characteristics } & \multicolumn{3}{|c|}{ With periodontitis } & \multicolumn{2}{|c|}{ Without periodontitis } & \multirow[t]{2}{*}{$p$-Value } \\
\hline & & $n$ & $\%$ & $n$ & $\%$ & \\
\hline \multirow[t]{2}{*}{ Length of suffering } & $>5 y$ & 33 & 70.2 & 14 & 29.8 & \multirow[t]{2}{*}{0.157} \\
\hline & $\leq 5 \mathrm{y}$ & 24 & 55.8 & 19 & 44.2 & \\
\hline \multirow[t]{2}{*}{ Family history } & Positive & 43 & 67.2 & 21 & 32.8 & \multirow[t]{2}{*}{0.234} \\
\hline & Negative & 14 & 53.8 & 12 & 46.2 & \\
\hline \multirow[t]{2}{*}{ Ages } & $>61$ & 29 & 54.7 & 24 & 45.3 & \multirow[t]{2}{*}{0.042} \\
\hline & $\leq 61$ & 28 & 75.5 & 9 & 24.3 & \\
\hline
\end{tabular}

Table 2 Correlation between behavioral (predisposing, enabling, and reinforcing) factors and the incidence of periodontitis in type 2 diabetes mellitus patients with and without periodontitis

\begin{tabular}{|c|c|c|c|}
\hline \multicolumn{4}{|l|}{ Diabetes mellitus } \\
\hline \multirow[t]{2}{*}{ Variables: behavior } & With periodontitis & Without periodontitis & \multirow[t]{2}{*}{$p$-Value } \\
\hline & Mean \pm SD & Mean \pm SD & \\
\hline Predisposing factor & $126.76 \pm 17.066$ & $129.76 \pm 12.659$ & 0.000 \\
\hline Enabling factor & $16.05 \pm 12.659$ & $16.48 \pm 2.431$ & 0.445 \\
\hline Reinforcing factor & $16.05 \pm 2.808$ & $22.12 \pm 2.891$ & 0.031 \\
\hline
\end{tabular}

Table 3 Correlation between lifestyle and the incidence of periodontitis in type 2 diabetes mellitus patients with and without periodontitis

\begin{tabular}{|c|c|c|c|c|c|c|}
\hline \multirow{3}{*}{ Variables: lifestyle } & \multicolumn{5}{|c|}{ Diabetes mellitus } & \multirow{3}{*}{$p$-Value } \\
\hline & \multicolumn{3}{|c|}{ With periodontitis } & \multicolumn{2}{|c|}{ Without periodontitis } & \\
\hline & & $n$ & $\%$ & $n$ & $\%$ & \\
\hline \multirow[t]{2}{*}{ Food style } & Poor & 17 & 81.0 & 4 & 19.0 & \multirow[t]{2}{*}{0.056} \\
\hline & Good & 40 & 58.0 & 29 & 42.0 & \\
\hline \multirow[t]{2}{*}{ Physical activities } & Poor & 55 & 64.0 & 31 & 36.0 & \multirow[t]{2}{*}{0.571} \\
\hline & Good & 2 & 50.0 & 2 & 50.0 & \\
\hline \multirow[t]{2}{*}{ Drug consumption } & Poor & 26 & 76.5 & 8 & 23.5 & \multirow[t]{2}{*}{0.044} \\
\hline & Good & 31 & 55.4 & 25 & 44.6 & \\
\hline \multirow[t]{2}{*}{ Management of oral cavity } & Poor & 23 & 65.7 & 12 & 34.3 & \multirow[t]{2}{*}{0.708} \\
\hline & Good & 34 & 61.8 & 21 & 38.2 & \\
\hline \multirow[t]{2}{*}{ Smoking } & Smoking & 15 & 70.0 & 5 & 30.0 & \multirow[t]{2}{*}{0.220} \\
\hline & Nonsmoking & 42 & 61.4 & 28 & 38.8 & \\
\hline
\end{tabular}


Table 4 Correlation between concentration of TNF- $\alpha$ and the incidence of periodontitis in type 2 DM patients with and without periodontitis

\begin{tabular}{|l|l|l|l|l|l|}
\hline Diabetes mellitus & $N$ & $\begin{array}{l}\text { With periodontitis } \\
\text { (mean } \pm \text { SD) }\end{array}$ & $N$ & $\begin{array}{l}\text { Without periodontitis } \\
\text { (mean } \pm \text { SD) }\end{array}$ & $p$-Value \\
of TNF- $\alpha$ levels & 57 & $0.628 \pm 0.123$ & 33 & $0.457 \pm 0.097$ & 0 \\
\hline & 5
\end{tabular}

Abbreviations: DM, diabetes mellitus; SD, standard deviation; TNF- $\alpha$, tumor necrosis factor- $\alpha$.

correlation between the concentration of TNF- $\alpha$ and the incidence of periodontitis in patients with type $2 \mathrm{DM}$ with and without periodontitis (-Table 4 ).

\section{Discussion}

The occurrence of periodontitis in patients with type $2 \mathrm{DM}$ increases with age due to the decrease in the physiological function of the body. According to Moore et al, the cumulative damage of a person's periodontal tissue gets worse with increasing age. Pancreatic $\beta$ cells begin to shrink continuously which results in reduced insulin secretion and also reduced receptor sensitivity. ${ }^{13,14}$ However, the long duration of diabetes and a family history of type $2 \mathrm{DM}$ are factors that aggravate type 2 diabetes, but they are not significantly associated with the incidence of periodontitis in type 2 DM patients.

Type $2 \mathrm{DM}$ is closely related to the behavior and lifestyle of the patients. One of the models commonly used to diagnose, treat, and prevent the disease is the PRECEDE-PROCEED model. ${ }^{15}$ However, only predisposition and reinforcement were found to have a significant correlation in this study, while the supporting factors were not. The factors represented by insurance ownership and the respondent's financial ability were not always proportional to the respondent's ability in controlling type 2 DM. Predisposition and reinforcement factors were significantly correlated in this study, especially in the consumption of antidiabetes drugs. The reinforcing factor had a significant correlation with the incidence of periodontitis in patients with type $2 \mathrm{DM}$. The findings in this study indicated that significant family and health care staff support provided fundamental changes to the lifestyle of people with type $2 \mathrm{DM}$ to be better so that the disease can be controlled.

Physical activity is a movement that is performed by the skeletal muscles that require energy. Exercise, however, is a planned, structured, repetitive, and intentional movement intended to improve or maintain physical fitness. Exercise improves blood glucose management in type 2 diabetes, reduces cardiovascular risk factors, contributes to weight loss, and improves well-being. ${ }^{16}$ Regular exercise can save or delay the development of type 2 diabetes. ${ }^{14}$ The demanding situation is related to blood glucose control range with diabetes type, hobby type, and the presence of diabetesrelated complications. $^{12,17}$

Physical activity referred to in the study was the activity with a duration of at least 30 minutes four to seven times a week. The significant difference found in the results of this study was because the physical activity was dominated by the elderly patients performing physical activities for less than a minimum duration of 30 minutes four to seven times a week. Physical activity can increase the sensitivity of insulin receptors so that glucose can be converted into energy. When physical activity is performed, the muscles in the body will react by using stored glucose.

The level of periodontal damage in diabetics is influenced by glycemic control, that is the consumption of antidiabetes drugs and the individual's immune system. Poor glycemic control and increased formation of AGE products cause oxidative stress to the gingiva, which exacerbates periodontal tissue damage. Significant support from the family and health care staff was able to provide the best glycemic control with regular consumption of antidiabetic drugs, and reduced periodontal tissue damage.

The behavior of oral cavity care in type $2 \mathrm{DM}$ patients was found not to have a significant correlation with the incidence of periodontitis. Two of five studies stated that there were significant changes in glucose levels in type 2 DM patients after periodontal treatment. This shows that oral cavity care in type 2 DM patients is not enough just by brushing the teeth, but with additional periodontal treatment in the form of scaling and root planning. ${ }^{18}$

Smoking behavior in people with type 2 DM has a significant relationship with the incidence of periodontitis. Smoking is a risk factor for the development of periodontal disease and alveolar bone loss is 20 times higher in type 2 DM patients. ${ }^{19}$ Type 2 DM patients who smoke have a deeper periodontal pocket than those who do not smoke. The nicotine in cigarettes has a short vasoconstrictive effect on the oral mucosa and cell metabolism. Smoking behavior was also found to support microbial growth in periodontal tissue. Smoking is also known to affect neutrophils and collagen, exacerbating periodontal conditions in people with type 2 DM.

Analysis of TNF- $\alpha$ levels in this study showed a significant correlation between TNF- $\alpha$ concentrations and the incidence of periodontitis in type $2 \mathrm{DM}$ patients with and without periodontitis. The results of this study confirmed a previous study that found that TNF- $\alpha$ had a close relationship with periodontitis and type $2 \mathrm{DM}^{20}{ }^{\mathrm{TNF}-} \alpha$ is produced as an inflammatory response in periodontitis and is an important additional factor in insulin sensitivity in type $2 \mathrm{DM}^{21,22}$ The high levels of inflammatory mediators, such as TNF- $\alpha$, contribute to increased insulin resistance. In addition, periodontal bacteria can migrate to the liver, inhibit insulin signaling, 
and result in decreased glycogen synthesis. ${ }^{23}$ Recent systematic reviews have shown that periodontal therapy can positively influence DM control. ${ }^{24}$ Age has a significant effect on TNF- $\alpha$ in patients with periodontitis and types $2 \mathrm{DM}^{25}$

The results of research performed on rats showed that TNF- $\alpha$ levels decreased in periodontic experimental animals that received DM and dietary treatment. ${ }^{26}$ In addition, based on the results of a study, ${ }^{27}$ it was found that TNF- $\alpha$ had a significant relationship with periodontitis and type $2 \mathrm{DM}$ in patients who received treatment. There was a decrease in TNF- $\alpha$ levels after drug consumption.

The limitation of this study was that the information obtained about the respondents, such as behavior and several other factors, was obtained by using a questionnaire, so that there was a possibility that the respondent did not answer according to reality. However, an anticipatory effort had been made to confirm the results by carrying out measurement using CPITN to assess the amount of bleeding on probing and the depth of the pocket. In a study conducted on rats, TNF- $\alpha$ levels decreased in those animals which experienced periodontitis and received DM and dietary treatment. It was found that TNF- $\alpha$ had a significant relationship in patients with periodontitis and type 2 diabetes who received treatment. It appeared that TNF- $\alpha$ levels in GCF and serum before treatment were higher in the GDM group than in the control group. Thus, TNF- $\alpha$ examination can improve understanding of the pathogenesis of periodontitis and GDM and its assessment in the treatment process can result in better disease control.

\section{Conclusion}

High levels of the inflammatory mediator, such as TNF- $\alpha$, might contribute to an increase in insulin resistance. Inflammation will be more severe in the presence of hyperglycemia because hyperglycemia causes an increase in proinflammatory cytokines like TNF- $\alpha$. TNF- $\alpha$ stimulates osteoclasts to mature and actively absorb bone. Periodontal bacteria can translocate to the liver, inhibit insulin signaling, and result in decreased glycogen synthesis. Poor glycemic control will increase the formation of AGE products that can induce oxidative stress on the gingiva, thereby aggravating damage to periodontal tissue. In patients with type $2 \mathrm{DM}$, periodontitis is prevented not only by regularly maintaining oral cavity health but also by controlling blood sugar levels by regularly consuming the drugs. Knowledge is a factor that affects adherence of people with type 2 DM in consuming drugs regularly, strengthened by family support which will ultimately play a role in reducing TNF- $\alpha$ levels.

\section{Ethical Approval and Consent to Participate}

This was an analytic observational study with a crosssectional approach, performed after accepting ethical clearance from the Faculty of Dental Medicine Universitas Airlangga, Universitas Airlangga, Surabaya, Indonesia, with Licensing Certificate Number 133/HRECC.FODM/VII/2018. Written informed consents were collected from 90 respondents with type $2 \mathrm{DM}$ with and without periodontitis who were taken as samples, and measurements were made on bleeding on probing and the depth of the pocket with CPITN. TNF- $\alpha$ was measured by ELISA, while questionnaires were used to measure behavior and lifestyle. All participants were in a position to understand and consent to the study requirements, and provided written informed consent.

\section{Availability of Data}

The datasets generated and/or analyzed in the course of the cutting-edge have a look at are not public to be had because of obstacles of moral approval regarding the affected person records and anonymity, however, are to be had from the corresponding creator on affordable request.

\section{Authors' Contributions}

T.B. conceived the presented idea and wrote the manuscript. G.R.S.W. wrote the manuscript and conceptualized the study. R.P. analyzed the data and performed the analytic calculations. D.S. performed the experiments. C. R.P. interpreted the data. All authors read and approved the final version of the manuscript.

\section{Conflict of Interest}

None declared.

\section{Acknowledgments}

The authors gratefully thank the Rector, the Head of Research and Innovation Center, the Dean and the Department of Dental Public Health, Faculty of Dental Medicine, Universitas Airlangga, Surabaya, Indonesia, and dental technicians who helped to complete this research.

\section{References}

1 American Diabetes Association. Diagnosis and classification of diabetes mellitus. Diabetes Care 2012;35(Suppl 1):S64-S71

2 International Diabetes Federation. IDF Diabetes Atlas, 6th ed. Brussels: International Diabetes Federation; 2018

3 WHO. Global Report on Diabetes. Geneva World Health Organization 2016

4 Hidayati Sri, Adin Mu“afiro, Joko Suwito. Analysis of factors related to the severity of periodontitis in patients with type 2 DM in diabetes RSU Dr. Soetomo Surabaya. Buletin penelitian RSU Dr. Soetomo 2008;10(02)

5 Deng T, Wang L, Lv J, et al. Association of three bacterial species and periodontal status in Chinese adults: an epidemiological approach. J Clin Microbiol 2011;49(01):184-188

6 Ghazanfari Z, Haghdoost AA, Alizadeh SM, Atapour J, Zolala F. A comparison of HbA1C and fasting blood sugar tests in general population. Int J Prev Med 2010;1(03):187-194

7 Green L. Health Promotion Planning: An Educational and Environmental Approach. Mountain View, CA: Mayfield Publishing Company; 2000

8 Fotek I. Periodontitis. Medline Plus Medical Encyclopedia; 2012

9 Newman MG, Takei H, Klokkevold PR, Carranza FA. Carranza's Clinical Periodontology. 11th ed., China: Elsevier Health Service; 2010:414-416

10 Sarafino EP, Smith TW. Health Psychology: Biopsychosocial Interactions. Hoboken: John Wiley \& Sons Inc.; 2012

11 Schellenberg ES, Dryden DM, Vandermeer B, Ha C, Korownyk C. Lifestyle interventions for patients with and at risk for type 2 
diabetes: a systematic review and meta-analysis. Ann Intern Med 2013;159(08):543-551

12 Taylor GW. The effects of periodontal treatment on diabetes. J Am Dent Assoc 2003;134:41S-48S

13 American Diabetes Association. Diagnosis and classification of diabetes mellitus. Diabetes Care 2009;32(Suppl 1):S62-S67

14 American Diabetes Association. Foundations of care and comprehensive medical evaluation. Sec. 6. In Standards of Medical Care in Diabetes 2016. Diabetes Care 2016;39(01):S23-S35

15 Chen L, Pei JH, Kuang J, et al. Effect of lifestyle intervention in patients with type 2 diabetes: a meta-analysis. Metabolism 2015; 64(02):338-347

16 Lin X, Zhang X, Guo J, et al. Effects of exercise training on cardiorespiratory fitness and biomarkers of cardiometabolic health: a systematic review and meta-analysis of randomized controlled trials. J Am Heart Assoc 2015;4(07):4

17 Colberg SR, Sigal RJ, Fernhall B, et al; American College of Sports Medicine American Diabetes Association. Exercise and type 2 diabetes: the American College of Sports Medicine and the American Diabetes Association: joint position statement. Diabetes Care 2010;33(12):e147-e167

18 Kim J, Amar S. Periodontal disease and systemic conditions: a bidirectional relationship. Odontology 2006;94(01):10-21

19 Kaval B, Renaud DE, Scott DA, Buduneli N. The role of smoking and gingival crevicular fluid markers on coronally advanced flap outcomes. J Periodontol 2014;85(03):395-405

20 Nishimura F, Iwamoto Y, Mineshiba J, Shimizu A, Soga Y, Murayama Y. Periodontal disease and diabetes mellitus: the role of tumor necrosis factor- $\alpha$ in a 2-way relationship. J Periodontol 2003;74(01):97-102

21 Martínez-Aguilar VM, Carrillo-Ávila BA, Sauri-Esquivel EA, et al. Quantification of TNF- $\alpha$ in patients with periodontitis and type 2 diabetes. BioMed Res Int 2019;2019:7984891

22 Esteves Lima RP, Cota LO, Silva TA, Cortelli SC, Cortelli JR, Costa FO. Periodontitis and type 2 diabetes among women with previous gestational diabetes: epidemiological and immunological aspects in a follow-up of three years. J Appl Oral Sci 2017;25(02):130-139

23 Qiao YC, Chen YL, Pan YH, et al. The change of serum tumor necrosis factor alpha in patients with type 1 diabetes mellitus: a systematic review and meta-analysis. PLoS One 2017;12(04): e0176157

24 Engebretson S, Kocher T. Evidence that periodontal treatment improves diabetes outcomes: a systematic review and metaanalysis. J Periodontol 2013;84(Suppl 4):S153-S169

25 Ishikawa M, Yoshida K, Okamura $\mathrm{H}$, et al. Oral Porphyromonas gingivalis translocates to the liver and regulates hepatic glycogen synthesis through the Akt/GSK-3 $\beta$ signaling pathway. Biochim Biophys Acta 2013;1832(12):2035-2043

26 Andrade EF, Silva VO, Moura NO, et al. Physical exercise improves glycemic and inflammatory profile and attenuates progression of periodontitis in diabetic rats (HFD/STZ). Nutrients 2018;10(11): 1702

27 Elkadi O, Madkour G, Elmenoufy H, Refai M. Evaluation of level of TNF- $\alpha$ in chronic periodontitis patients with gestational diabetes mellitus after phase I periodontal therapy. Adv Dent \& Oral Health 2018;9(03) 